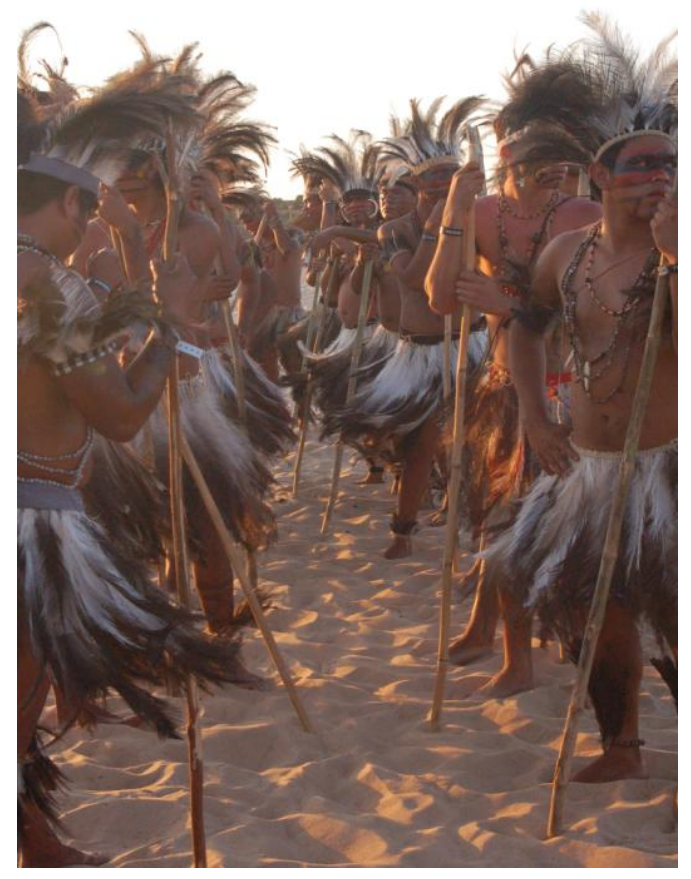

\title{
Jogos dos povos indígenas: Da aldeia para cidade e as representações urbanas
}

Games of indigenous peoples: the village to city urban and representations

\section{Resumo:}

Maria Beatriz Rocha Ferreira ${ }^{1}$ Vera Regina Toledo Camargo ${ }^{2}$

Os jogos dos povos indígenas realizados na cidade representam novas formas de celebrar, de jogar, de transpor obstáculos, e de superação. São eventos urbanos considerados de massa, constituem campos intrigantes de pesquisas, com implicações interdisciplinares socioantropológicas e comunicacionais. São locais de convivência de saberes ancestrais, de reflexão sobre as práticas corporais e suas inter-relações políticas e sociológicas, campos de lutas, de representatividade, poder e conquistas.

Palavra Chave: Jogos Indígenas, práticas corporais, jogos indígenas na cidade

\section{Summary}

The indigenous peoples' games held in the city represent new ways to celebrate, to play, to overcome obstacles, and overcoming. The events are urbans and considered of mass. They are intriguing fields of research, with socio-anthropological, interdisciplinary and communicational implications. They are places of ancestral knowledge, of reflection on bodily practices and their political and sociological interrelationships, fields of struggle, of representations, power and achievements.

Keyword: Indigenous peoples, games, bodily practices, indigenous games in the city

\footnotetext{
1 Livre docente pela Faculdade de Educação Física da Unicamp, doutora em Antropologia pela Universidade do Texas, pós doc Universidade Católica de Leuven, Bélgica, coordenadora do Laboratório de Antropologia Bio-cultural - FEF-UNICAMP, 1988 - 2012. Desenvolve pesquisas em antropologia do jogo, esporte e povos indígenas. Professora do programa CAPES/PNVS/ Universidade Federal da Grande Dourados. Mato Grosso do Sul. E-mail - beatrizdevloo@gmail.com

${ }^{2}$ Doutora em Comunicação com pós-doutorado em Multimeios. Pesquisadora do Laboratório de Estudos Avançados em Jornalismo e Professora credenciada no Mestrado em Divulgação Cientifica e Cultural (Labjor-Unicamp), Caixa Postal 6060-CEP 13083970-Campinas SP, verartc@ unicamp.br.
} 


\section{Os jogos indígenas na cidade}

Os eventos dos jogos indígenas são realizações urbanas. É um campo que congrega diferentes conhecimentos e significados socioculturais ancestrais e contemporâneos. As redes que se formam para tal organização têm caráter permanente e temporário. Fazendo uma retrospectiva do início desse movimento, o líder Mariano Marcos Terena ${ }^{3}$ deixa claro os objetivos que os impulsionaram nesta trajetória: a idealização de eventos "sem doping, sem anabolizantes", de modo que se possa celebrar com "a alma, com o coração", enfim, desenvolvendo um "novo conceito de esporte" (TERENA, 2003), na imagem 1, a concepção do cenário dos jogos.

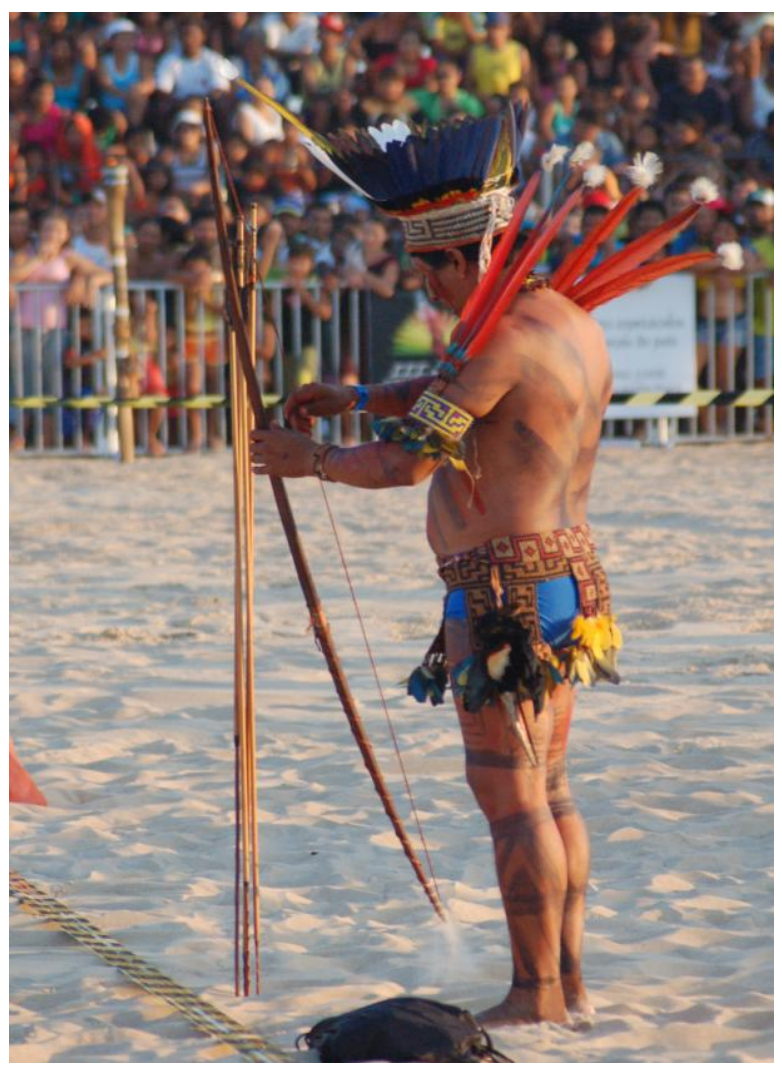

Imagem 1 -Índio Pareci, na competição de arco e flecha - Vazquez 2007

Um sonho idealizado pelos irmãos da etnia Terena: Carlos e Marcos, que desde a década de oitenta, em visita a várias comunidades indígenas, vislumbraram que as expressões de alegrias dos povos indígenas brasileiros, oriundas de suas manifestações culturais, estavam muito presentes quando da preparação de seus enfeites plumários, contornos dos desenhos, de suas pinturas corporais, danças, cantos, instrumentos musicais e nos esportes tradicionais. Compreenderam que a partir dessas manifestações

\footnotetext{
${ }^{3}$ Entrevista realizada em 2006, com a professora Maria Beatriz Rocha Ferreira.
} 
poderiam ser (re)conhecidos e (re)significados pela sociedade. Foi desta maneira que surgiu a ideia de juntar essas atitudes positivas, para mostrá-las aos não-índios e dar visibilidade e a importância da cultura indígena na sociedade brasileira.

A primeira iniciativa de aproximar as práticas corporais dos índios com a sociedade do "branco" foi quando um índio "flecheiro" se apresenta nos Jogos Estudantis Abertos (JEBs) em São Paulo, em 1985. Sobre essa ação Terena menciona que: "o índio estava usando um arco 'tradicional', uma metodologia 'tradicional' com um objetivo que não era 'tradicional'..., pois na aldeia ele faz aquilo para acertar uma ave, uma anta, um peixe no meio do rio". A partir desses Jogos Escolares Brasileiros começou-se a trabalhar o conceito de Jogos dos Povos Indígenas. Os representantes se reuniram com o então ministro do Esporte, nos anos 90, Edson Arantes do Nascimento, Pelé, e nasceu a ideia de se fazer uma Olimpíada Indígena. Marcos Terena menciona que se utilizassem o termo "jogos indígenas" na época poderia dar a conotação de futebol para os indígenas. E, portanto, optou-se por Olimpíadas.

A primeira experiência dos Esportes Indígenas foi na cidade de Goiânia (GO), em 1996, e a partir daí adquiriu-se experiência e o formato dos jogos foi sendo modificado a cada edição dos Jogos (TERENA, 2003).

O sonho se torna realidade e já foram realizados eventos em Guairá (PR), em 1999, Marabá (PA), em 2000, Campo Grande (MS), em 2001, Marapani (PA), em 2002, Palmas (TO), em 2003, Porto Seguro (BA), em 2004, Fortaleza (CE), em 2005, e Recife e Olinda (PE), em 2007, Paragominas (PA), em 2009, Porto Nacional (TO) em 2011 e a décima segunda edição a ser realizada em 2013, em Cuiabá.

As informações trabalhadas neste texto foram obtidas através de (a) fontes bibliográficas na perspectiva de conceituação e mais especificamente nas (b) pesquisas etnográficas realizadas nos Jogos Estaduais de Conceição do Araguaia (PA), 2006, Campos Novos dos Paresis (MT), 2007; nos Jogos dos Povos Indígenas de caráter nacional em Recife/Olinda (PE), 2007, Paragominas/TO (2009), Porto Nacional/TO (2011) e nas Festas do Índio em Bertioga (SP), 2004 e 2006 de caráter regional. Nestes eventos foram realizadas entrevistas com líderes indígenas que os acompanhavam, "atletas" indígenas (termo denominado por eles) no alojamento dos jogos, filmagens e também na área dos jogos e alojamentos.

Diferentes setores da sociedade se envolvem na organização dos jogos, a saber: Comitê Intertribal Memória e Ciência Indígena (ITC), governo federal (através dos ministérios dos Esportes, da Educação e da Cultura - âmbito nacional - secretarias de 
Esporte estaduais e/ou municipais - âmbito estadual e municipal), e também universidades, ONGs, mídia nacional e internacional. As universidades brasileiras e do exterior estão presentes participando com palestras nos fóruns, apresentando pesquisas que muitas vezes se desdobram em projetos comuns. Nesses eventos, mas em locais diferentes, ocorre o Fórum Social e a feira de artesanato indígena.

\section{"O importante é celebrar e não competir"}

A imagem 2, apresenta uma índia competindo com arco e fecha, demonstrando muito bem o lema da competição. Este é o lema propulsor dos jogos e que se concretiza a cada evento. Carlos Terena (2007, pg. 29) menciona que:

“os jogos indígenas seguem o princípio das tradições transmitidas oralmente e atualizadas de geração em geração. Os participantes não têm o objetivo de ganhar. Valorizam, sobretudo, a oportunidade de comemorar, sendo que a primeira atividade dos jogos é de caráter espiritual. Os pajés são os primeiros a entrar na arena para agradecer ao Grande Criador e pedir forças para afastar a carga negativa”.

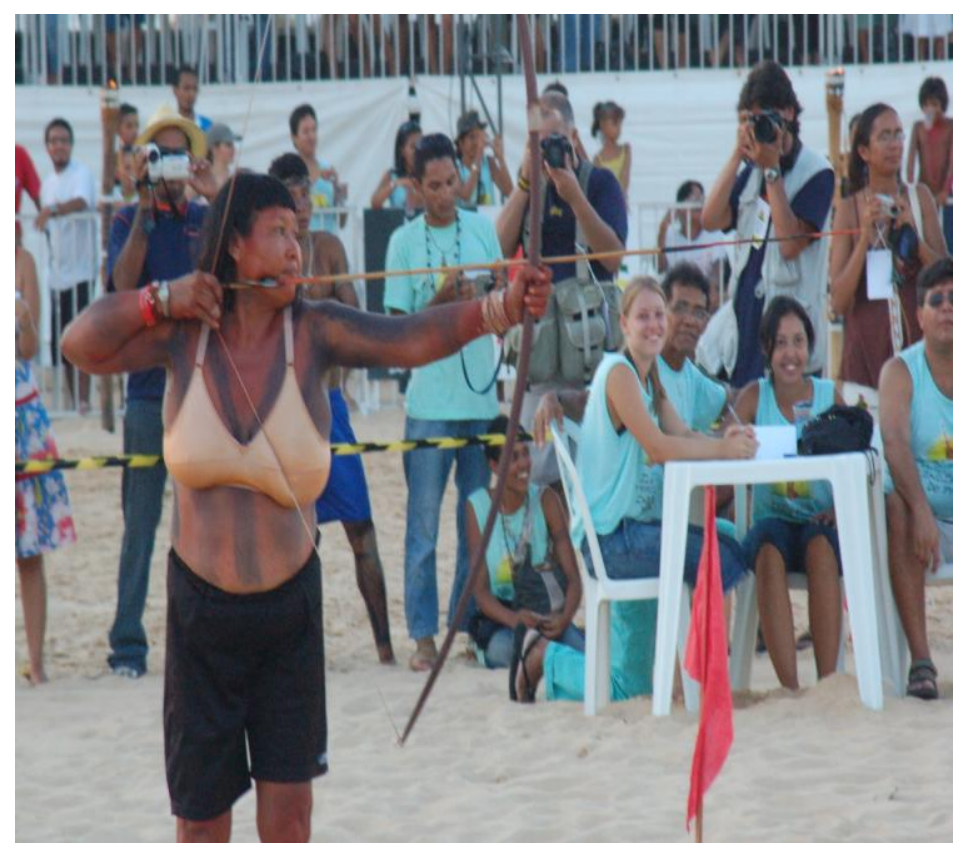

Imagem 2 Índia participa da competição de arco e flecha participa homens e mulheres, de qualquer idade. Vazquez 2007

O celebrar e não o competir vem quase na contramão do imaginário social do esporte, pois vivemos numa sociedade competitiva, racionalista, onde o esporte está inserido. Este espírito competitivo está embutido no comportamento das pessoas, do público, da mídia, das ações governamentais e não governamentais, etc. 
Contrapondo com a filosofia, o locutor do evento, os jornais que estampam a disputa e a televisão que transmitem, todos incentivam a competição. As pessoas são estimuladas a torcerem por uma equipe ou outra, mesmo sem enxergar bem as demonstrações de arco, flecha ou outras atividades, mas pelo incentivo do locutor clamando por torcida. Para romper com esse espírito é preciso um esforço de todas as pessoas envolvidas no processo para se atualizarem constantemente e estabelecerem novas formas de diálogos e construções sociais. Afinal será que o cenário dos jogos é mais uma ação para presentificar a cultura indígena na sociedade mais ampla?

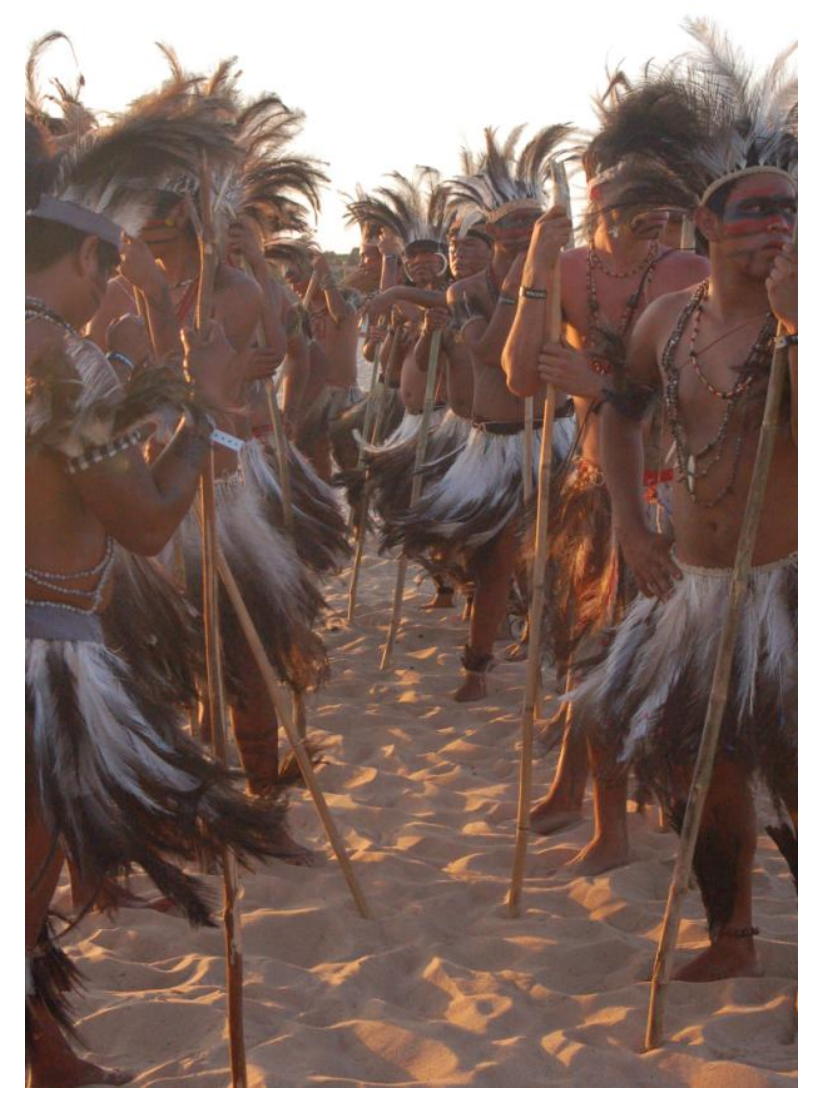

Imagem 3: Índios da etnia Terena, preparando-se para a dança do avestruz, Vazquez, 2007

As implicações do lema "o importante é celebrar e não competir" leva a diferentes concepções organizacionais. Por exemplo, as regras dos jogos podem ser mudadas para se aproximarem da vida cotidiana, da caça, da pesca, e sujeitas a decisões do momento, nem sempre racionais. Esse tipo de pensamento é difícil de ser entendido no mundo dos esportes, onde as regras são estabelecidas a priori, sob a autoridade de federações e confederações. 
Carlos Justino Terena relata ${ }^{4}$ três situações diferentes na qual alguns indígenas preferiram não ganhar a prova nos jogos de futebol (Goiânia, 1996, e Marabá, 2000) e nas provas de canoagem (VI Jogos de Palmas, em 2003) para que outros também pudessem ganhar.

O sentido de campeão, de vencedor, para os indígenas, pode estar próximo ao sentido do agon na Grécia antiga. A expressão agon significa assembleia, reunião, combate com características competitivas. Naquela sociedade havia a busca de equilíbrio entre a estética, a competição leal, a premiação justa e a liderança. Eles não se opunham a um rival propriamente, mas à força física, à velocidade, à memória, etc.

O importante, para os gregos, era o espírito competitivo e não necessariamente o resultado em si. (ROCHA FERREIRA \& VINHA, 2007, CAILLOIS, 1986, HUIZINGA, 1993). A imagem 3 apresenta essa imagem do guerreiro, muito bem representada por todos os participantes.

Nos Jogos dos Povos Indígenas, os organizadores querem trazer o espírito de guerreiro, de auto superação presente nos indígenas; nos rituais de passagens, nos embates e nas lutas, dentre outros, não para "vencer a qualquer custo", de forma desmedida, mas mais próximo ao sentido do agon. (ROCHA FERREIRA \& VINHA, 2007).

Depoimentos de líderes indígenas ${ }^{5}$ indicam que o evento é organizado para os "brancos" e precisa haver elementos da sociedade urbana para atrair o público. O processo de construção desses eventos não é simples. Inicia com a passagem dos jogos da aldeia para a cidade e são representações miméticas. Taussig (1993) menciona que a faculdade mimética pertence à "natureza" que tem a cultura de criar uma "segunda natureza". Essa faculdade, no entanto, não se dá meramente pela cópia do original, mas pelas ressignificações que cada cultura consegue do original e como influencia este original.

Os jogos não são, portanto, cópias do original, dos rituais, das atividades corporais realizadas na aldeia, mas a partir dessas atividades são ressignificados num outro momento e espaço e os Jogos Indígenas Urbanos ganham essas conotações.

Elias e Dunning (1992) nos estudos do lazer e futebol nos trazem uma característica importante da mimesis - relacionam-na com um aumento de tensão,

\footnotetext{
${ }^{4}$ Em entrevista as autoras,

${ }^{5}$ Entrevista realizada para as autoras
} 
(...) aquilo que as pessoas procuram nas suas atividades de lazer não é o atenuar de tensões, mas, pelo contrário, um tipo específico de tensão, uma forma de excitação relacionada, como notou Santo Agostinho, com o medo, a tristeza e outras emoções que procuraríamos evitar na vida cotidiana. (ELIAS e DUNNING, 1992, p.128)

Os jogos realizados nas aldeias, nos rituais e cerimônias sagradas desencadeiam tensão e/ou excitação. Entretanto, lembramos que aqueles comportamentos que geravam tensão/excitação no passado, não necessariamente se fazem no presente. Essas tensões/excitações são ressignificadas nos eventos realizados na cidade.

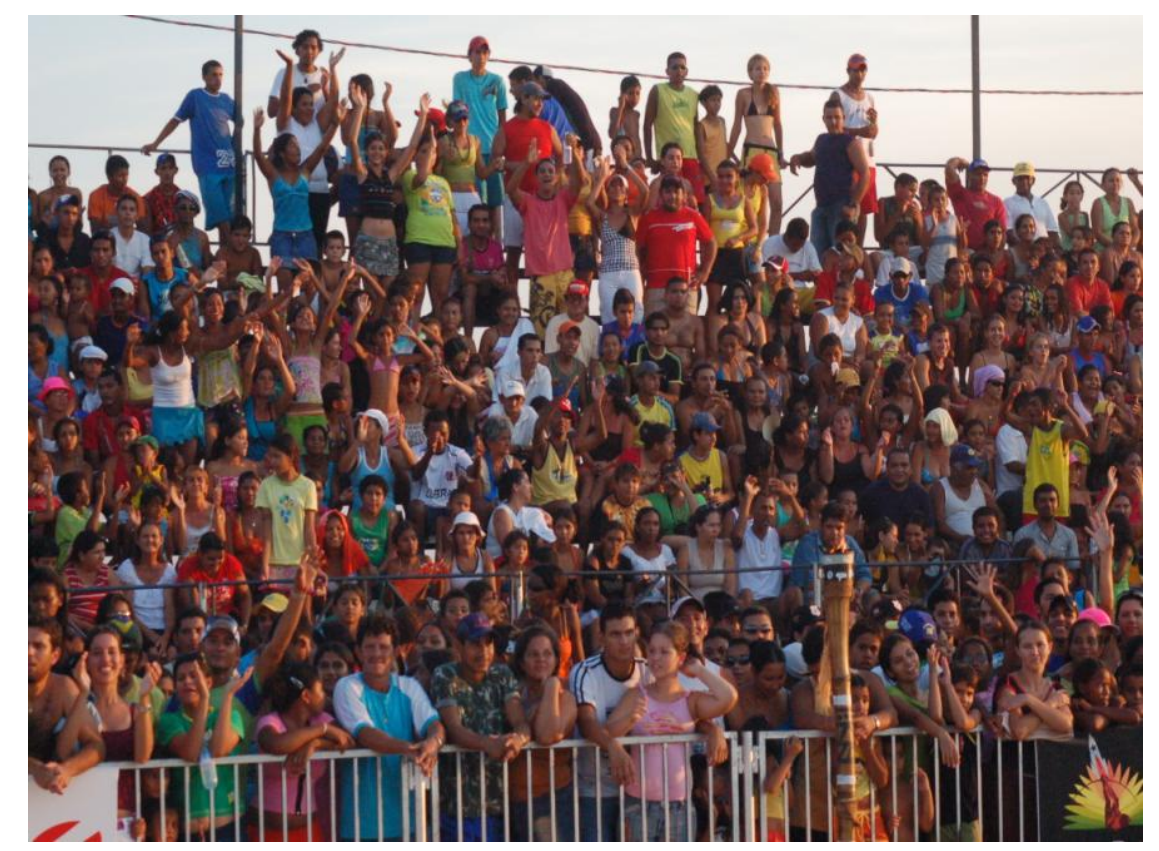

Imagem 4: Arquibancada do evento e a participação do público. Vazquez, 2007

\section{Encontros e desencontros de mundos}

Se, por um lado, há necessidade de se organizar os eventos para atender os procedimentos burocráticos dos ministérios e das secretarias de Esportes envolvidas, por outro, é necessário também seguir os rituais espirituais.

As escolhas do local e período lunar são selecionadas seguindo preceitos indígenas. As instalações da arena e hospedagens diferem de evento para evento, em alguns são construídas arenas circulares e ocas para repouso, outros são realizados em campo de futebol de médio porte ou em dependências das escolas ou colônias de férias para servir de hospedagem. Essas decisões dependem das condições locais e disponibilidade de verba do governo.

Os jogos, propriamente ditos, congregam os seguintes rituais e espaços: 
(a) lançamento ritualístico dos jogos realizados alguns meses com antecedência

(b) cerimonial de abertura com uma pajelança e acendimento da pira olímpica, realizado um dia antes da abertura dos jogos, antes ao entardecer;

(c) abertura propriamente dita dos jogos, com desfile de abertura realizada na arena, onde as etnias entram com roupas típicas, acendimento do fogo de maneira tradicional, danças e discursos oficiais de políticos e líderes indígenas.

(d) jogos, danças e rituais realizados durante o evento

(e) tendas de artesanatos,

(f) local de alimentação comunitária (tipo bandejão)

(g) alojamento construído de maneira típica ou em local apropriadado como colônia de férias, onde cada etnia tem seu local separado.

(h) fórum social - com convidados indígenas e não indígenas nacionais e internacionais, visando debater temas tais como educação, saúde, ecologia e juventude, comunicações, utilização de energia solar, reflexões sobre os jogos e esportes indígenas, etc.

A diversidade cultural dos povos pode ser vista nas plumagens, pinturas corporais, danças e nos jogos. Mas, subjacente ao visual, há a cultura imaterial, o como fazer, o quando fazer, o quanto fazer, que não se percebe. Há a vontade dos povos indígenas mostrarem os diferentes aspectos de suas culturas e tornarem-se visíveis para uma sociedade que não os reconhece e que acreditava no desaparecimento deles. Os jogos contribuem para os processos de revitalização cultural.

Compreendemos que os Jogos dos Povos Indígenas apresentam as seguintes categorias:

- As atividades de sobrevivência do cotidiano das aldeias, como arco, flecha, canoagem utilizados na caça e na pesca;

- Os rituais sagrados e as danças

- As atividades inseridas em rituais como corrida de toras, lutas corporais;

- Outras de caráter geral, incorporadas de outras culturas como o jogo cabo de guerra e futebol. 


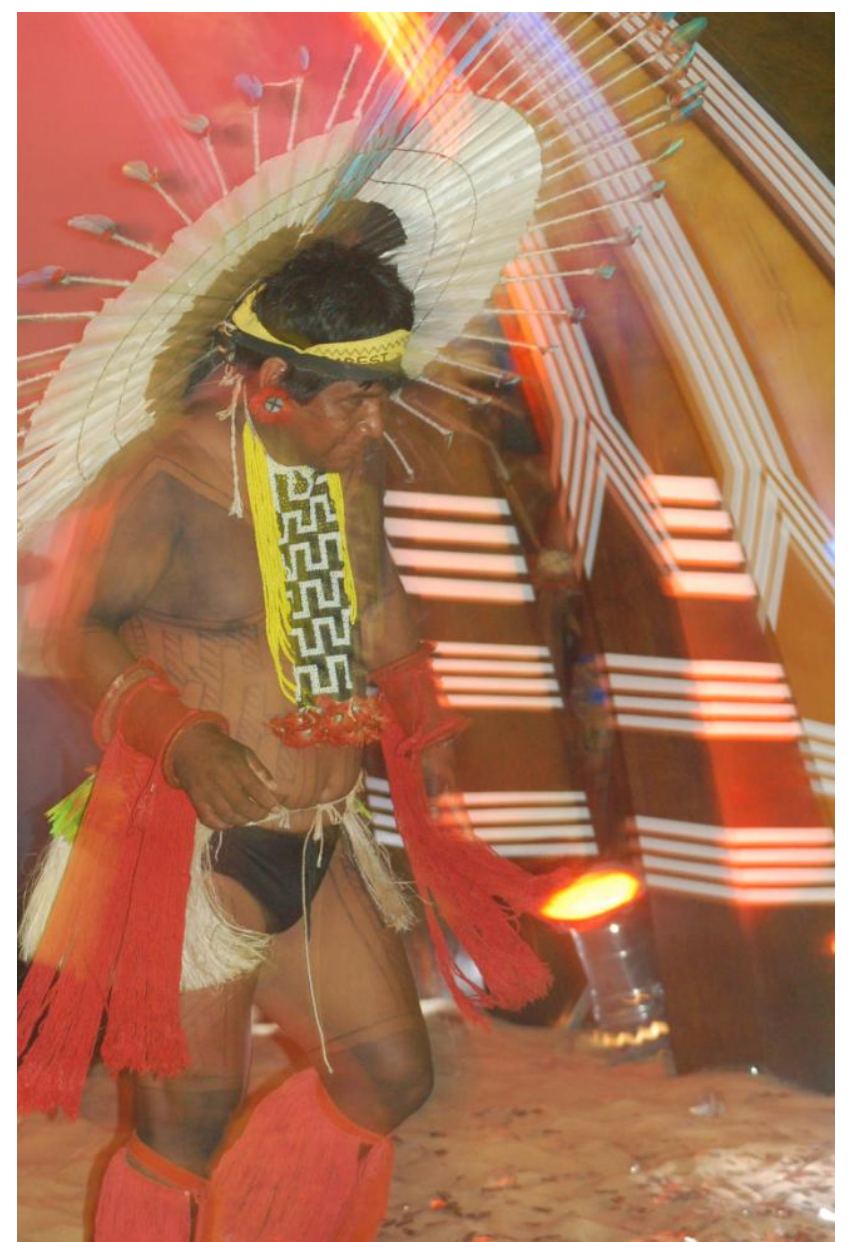

Imagem 5- Índio na cerimônia de abertura dos Jogos- Vazquez, 2007

Uma grande questão, sempre presente é a questão da tradicionalidade, como fica presente nestes dois mundos?O termo "tradicional" não deve ser usado para gerar ou enfatizar estereótipos, para congelar a idéia de mudança. Na imagem 5, observamos uma imagem tradicional do índio com suas vestimentas no desfile de abertura dos Jogos. De acordo com Gallois (2006):

(...)tradicional no saber tradicional não é a sua antigüidade, mas a maneira como ele é adquirido e como é usado" continuamente na produção do conhecimento. (p.20),

Neste sentido, é importante buscar compreender os jogos e esportes como processos dinâmicos inter-relacionados com as mudanças presentes na sociedade.

A propósito, não se pode revitalizar integralmente algo que está em desuso e talvez esquecido. Mas revitalizar ou reconstituir alguns de seus fragmentos através da memória. 
Esta por sua vez é seletiva, está circunscrita em lembranças e esquecimentos e passa muitas vezes por filtros emocionais. No caso dos indígenas, muitos dos jogos em desuso foram deixados de serem praticados e esquecidos por processos de repressão física e/ou psicológica, tais como o desenvolvimento de sentimento de vergonha, por serem considerados, através de seus comportamentos violentos e estarem inseridos em rituais categorizados como demoníacos, contrários à ética cristã dos colonizadores.

Os Jogos dos Povos Indígenas, no entender dos indígenas, propiciam "mostrar e revitalizar a cultura, as tradições e os valores, a aproximação e trocas de informações entre os 'parentes', a discussão de problemas, a confraternização, aprender a conhecer e respeitar outras etnias e línguas, vender artesanato, mostrar para o branco as diferenças, obter reconhecimento e ser respeitado. O indígenas não eram unido. A gente estava muito disperso" (VAZQUEZ et alli, 2006).

Podemos enfatizar que além das competições, os jogos são mais que um local de ressignificação para as mulheres que estão cada vez mais atuantes não só como esposas e mães, mas como atletas e lideranças políticas. (KOK \& ROCHA FERREIRA, 2011).

O evento propicia um estranhamento e uma aproximação entre o público e os indígenas. A logística organizacional difere das festas, celebrações e outras atividades realizadas nas aldeias. As decisões na cidade são feitas obedecendo a um calendário de atividades dos governos federal, estadual e/ou municipal, a disponibilidade financeira das entidades organizadoras, de prazos estabelecidos prioritariamente, de concorrências públicas, de rubricas financeiras que precisam ser seguidas, entre outros encargos. A prestação de contas é extremamente difícil, até para os experts no assunto. Enfim, são sociedades e lógicas diferentes que se predispõem a organizar o evento.

Os Jogos dos Povos Indígenas constituem-se espaços políticos de contato interétnicos. As lideranças indígenas transpõem barreiras historicamente hostis e excludentes aos seus povos e ampliam a rede de figurações ao vincular suas ações ao Estado, aos movimentos sociais indígenas, às universidades, a outras organizações não governamentais. O mais importante do legado dos jogos é que suas atividades não fazem parte de uma competição, é uma verdadeira festa com muitos rituais e, as identidades culturais de cada etnia estão representadas. São várias as manifestações das práticas corporais que fazem parte dos rituais que são realizadas nas aldeias, mas que ganham ressignificações quando apresentadas na cidade, como é o caso da corrida com toras. $\mathrm{Na}$ aldeia (caça representam a produtividade sociológica das metades, os clãs, o 
faccionalismo, o parentesco, as relações com a natureza e com os animais e pesca) e nos jogos tem o caráter um caráter demonstrativos para o público, e de valorização de identidades. A corrida de tora, como exemplo, está sendo representada na imagem 6.

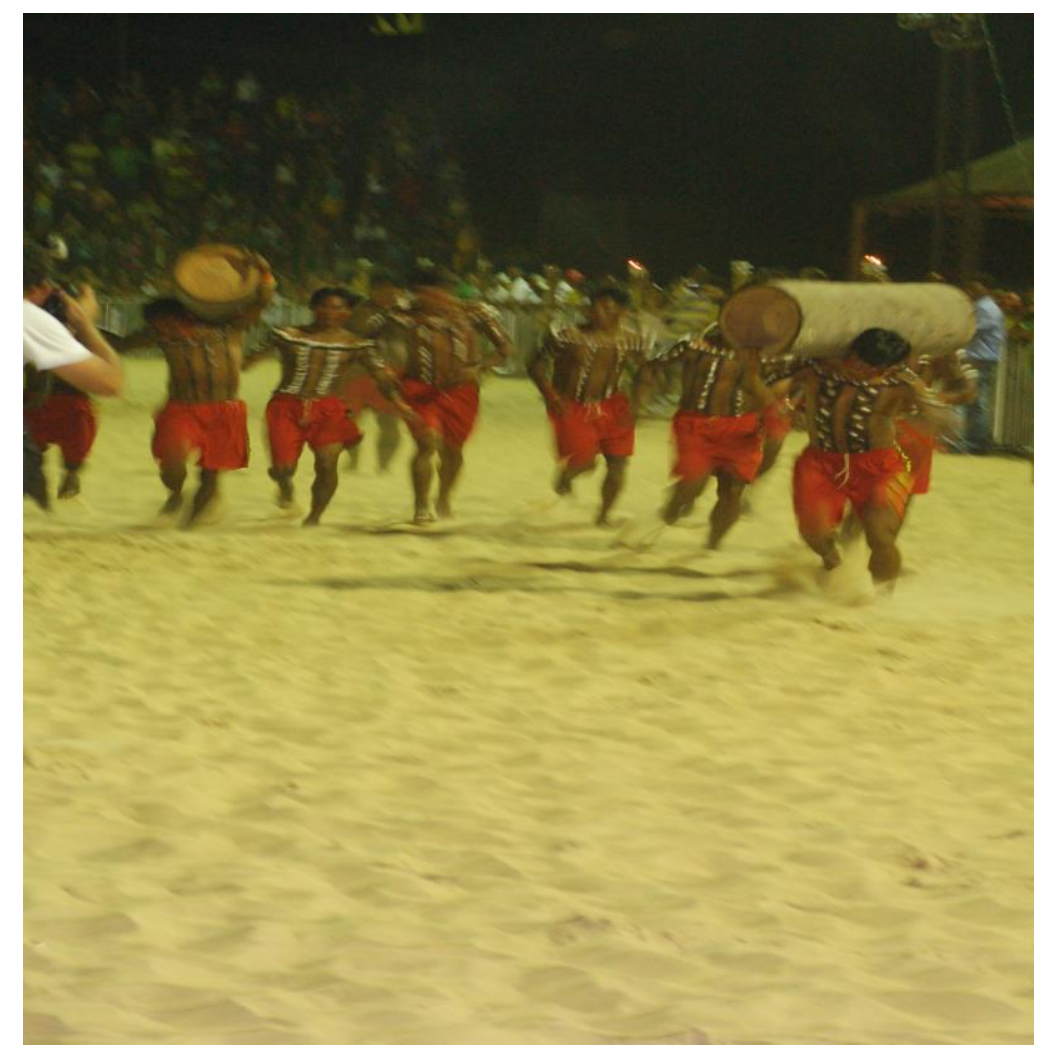

Imagem 6- Corrida de Toras, com a etnia GaviãoVazquez 2007

Verificamos nestes anos de pesquisa, que os jogos propiciam a construção de novas identidades, revitalizam as práticas corporais, celebram o espírito de confraternização com a sociedade não-indígena, cultivam a espiritualidade e divulgam as culturas dos povos indígenas na sociedade mais ampla e exercem os seus direitos como cidadãos brasileiros.

As imagens que ilustram este artigo são do professor Dr. Manuel Hernandez Vazquez, do Instituto de Educação Física de Madri, Espanha. Fotos dos Jogos dos Povos Indígenas de Recife e Olinda em 2007.

\section{Referências bibliográficas}

Caillois, R. (1986) Los juegos y los hombres: la máscara y el vértigo. México, D. F.: Fondo de Cultura Econômica.

Elias, N. \& Dunning E (1992) A busca da excitação. Lisboa: Difel.

Gallois, D.T. (2006)Patrimônio cultural imaterial e povos indígenas. IEPE, USP. 
Huizinga, J. (1993) Homo Ludens; o jogo como elemento da cultura. São Paulo: Perspectiva.

Kok, G. \& Rocha Ferreira, M.B(2011). Jogos nacionais: espaços de visibilidade da mulher indígena. In: Jogo, celebração, memória e identidade. Reconstrução da trajetória de criação, implementação e difusão dos Jogos dos Povos Indígenas no Brasil (1996 - 2009). Ed. Curt Nimuendajú.

Rocha Ferreira, M. B. \& Vinha, M.(2007) "Olimpíadas na floresta". Revista de História da Biblioteca Nacional.

Terena, C. J(2007) "O importante não é ganhar, mas celebrar". Revista de História da Biblioteca Nacional.

Terena, M.(2003) O Esporte como resgate de Identidade e Cultura. In: Cultura Corporal Indígena. Guarapuava: Ed. Unicentro.

Taussig, M. (1993)Mimesis and alterity: a particular history of the senses. New York/London: Routledge.

Vázquez, M.H.; Gómez, A.S.K.; Martin, P.J.J.; Vicente, D.B.R.; Rocha Ferreira, M.B.; Camargo, V.R.T.(2006) "Cultura de los Jogos dos Povos Indígenas". In: Perspectivas actuales de la animación sociocultural. Cultura, tiempo livre y participación social. Victor J. Ventosa (coord.). Editorial CCS, Alcalá, 166/28028 Madrid. 
Para citar essa obra:

FERREIRA, M. B. R.; CAMARGO, V. R. T. Jogos dos povos indígenas: da aldeia para a cidade e suas representações. In: RUA [online]. 2014, no. 20. Volume II - ISSN 14132109. p. 60-72. Consultada no Portal Labeurb - Revista do Laboratório de Estudos Urbanos do Núcleo de Desenvolvimento da Criatividade.

http://www.labeurb.unicamp.br/rua/

Capa: Índios da etnia Terena, preparando-se para a dança do avestruz, Vazquez, 2007

Laboratório de Estudos Urbanos - LABEURB

Núcleo de Desenvolvimento da Criatividade - NUDECRI

Universidade Estadual de Campinas - UNICAMP

http://www.labeurb.unicamp.br/

Endereço:

LABEURB - LABORATÓRIO DE ESTUDOS URBANOS

UNICAMP/COCEN / NUDECRI

CAIXA POSTAL 6166

Campinas/SP - Brasil

CEP 13083-892

Fone/ Fax: (19) 3521-7900

Contato: http://www.labeurb.unicamp.br/contato 